\title{
Definition of hemodynamic stability in blunt trauma patients: a systematic review and assessment amongst Dutch trauma team members
}

\author{
S. A. I. Loggers ${ }^{1}$ (1) $~$ T. W. A. Koedam ${ }^{1}$ G. F. Giannakopoulos ${ }^{1} \cdot$ E. Vandewalle ${ }^{2}$ \\ M. Erwteman ${ }^{3}$ W. P. Zuidema ${ }^{1}$
}

Received: 1 September 2016 / Accepted: 21 November 2016 / Published online: 30 November 2016

(C) The Author(s) 2016. This article is published with open access at Springerlink.com

\begin{abstract}
Introduction Trauma is a great contributor to mortality worldwide. One of the challenges in trauma care is early identification and management of bleeding. The circulatory status of blunt trauma patients in the emergency room is evaluated using hemodynamic (HD) parameters. However, there is no consensus on which parameters to use. In this study, we evaluate the used terms and definitions in the literature for HD stability and compare those to the opinion of Dutch trauma team members.

Method A systematic review was performed to collect the definitions used for HD stability. Studies describing the assessment and/or treatment of blunt trauma patients in the emergency room were included. In addition, an online survey was conducted amongst Dutch trauma team members.

Results Out of a total of 222, 67 articles were found to be eligible for inclusion. HD stability was defined in $70 \%$ of these articles. The most used parameters were systolic blood pressure and heart rate. Besides the variety of parameters, a broad range of corresponding cut-off points is noted. Despite some common ground, high inter- and intra-variability is seen for the physicians that are part of the Dutch trauma teams.
\end{abstract}

S. A. I. Loggers

s.loggers@vumc.nl

1 Department of Trauma Surgery, VU University Medical Center, 7F029, De Boelelaan 1117, 1007 MB Amsterdam, The Netherlands

2 Department of Emergency Medicine, VU University Medical Center, Amsterdam, The Netherlands

3 Department of Anesthesiology, VU University Medical Center, Amsterdam, The Netherlands
Conclusion All authors acknowledge HD stability as the most important factor in the assessment and management of blunt trauma patients. There is, however, no consensus in the literature as well as none-to-fair consensus amongst Dutch trauma team members in the definition of HD stability. A trauma team ready to co-operate with consensusbased opinions together with a valid scoring system is in our opinion the best method to assess and treat seriously injured trauma patients.

Keywords Hemodynamic instability $\cdot$ Hypovolemic shock $\cdot$ Primary survey $\cdot$ Blunt trauma $\cdot$ Triage $\cdot$ Trauma team

\section{Introduction}

Trauma is a global phenomenon. In 2008, 5.1 million people ( $9 \%$ of total deaths) died worldwide as a result of injury. Injuries also account for $17 \%$ of the disease burden in adults aged 15-59 years in 2004 [1, 2].

Most deaths are caused by unintentional injuries including blunt trauma such as falls or road accidents. Blunt trauma accounts for an estimated $50 \%$ of the mechanism of injury proportion [1].

The assessment of the hemodynamic (HD) status in blunt trauma patients is vital for early identification and timely management of a potential hemorrhage to keep the time between injury and intervention to a minimum. In order to improve trauma care furthermore, evidence-based practice guidelines are designed and implemented in every hospital. These management schemes are often based on the presence or absence of HD stability, proposed by the American College of Surgeons Advanced Trauma Life Support (ATLS) guidelines [3]. 
When the patient is unstable, time is a luxury and immediate surgical intervention in combination with resuscitation is mandatory $[4,5]$. When the patient is stable, more time is available for the assessment of the patient's injuries.

Systolic blood pressure (SBP) and heart rate (HR) have traditionally been used for recognition of the shock state in ATLS and Prehospital Trauma Life Support (PTLS) guidelines $[3,6]$. However, the value of these vital signs and their cut-off points have been disputed by some [7-12].

Despite the importance of the HD status of blunt trauma patients, several hemodynamic parameters [e.g., HR, respiratory rate (RR), blood pressure (BP), SPB and Revised Trauma Score (RTS)] with different cut-off points are used without general consensus about the best evidence-based practice. A combination of the traditional signs BP and HR, named Shock Index (SI) (calculated by HR/SBP), has been shown to identify beginning hemorrhage [13], need for massive transfusion [14] and predicting mortality [11, 15] more early and better than the vital signs apart.

As the initial assessment of a trauma patient concerns a multidisciplinary approach by the examining anesthesiologist, trauma surgeon and the emergency physician in the emergency room, it is important for everyone to speak the same language. Different specialities, however, bring different opinions about the best treatment if there is no clear consensus about the interpretation of all parameters. The meaning of HD instability in trauma patient is still very wide with unclear borders and lacks a clear validated definition that states which indicative parameters to use to initially assess the circulatory status.

This study assesses the definitions used for HD stability in a systematic review of the literature combined with a survey of the interpretations of HD instability in blunt trauma patients in the ER amongst Dutch trauma team members in order to establish the level of consensus about HD stability for blunt trauma patients.

\section{Method}

\section{Review of the literature}

A systematic search of the literature was conducted using the computerized bibliographic database MEDLINE and Embase. Both were searched for English and Dutch articles published from 2005 to 2015 concerning the diagnostics and/or treatment of adult patients suffering exclusively from blunt injury. The following combination of MeSH terms were used in the literature search: blunt trauma AND diagnostics OR management AND hemodynamic instability (full search available upon request).

Studies describing patients with severe neurological injuries, septic shock and/or chronic injuries, as well as studies of which the full text article was not available or articles published in another language than English or Dutch were excluded. Studies with less than ten patients, patients aged under 16 years, reviews and studies discussing predictive values in trauma patients rather than focusing on diagnosing and treating primary injuries were also excluded (see Fig. 1). Abstracts were independently screened by two different authors for inclusion criteria. If there was disagreement between the two authors, the opinion of a third authors was decisive. After abstracts were screened for eligibility, this procedure was repeated for the full text. After studies were found to be eligible for inclusion, the hemodynamic parameters, corresponding cut-off points and timing, type and amount of fluid resuscitation used for the definition of HD stability were processed in an SPSS $22^{\circledR}$ database.

\section{Survey amongst trauma team members}

In addition to the systematic review of the literature, an internet based survey study using a questionnaire was sent to all trauma surgeons, emergency MDs and anesthesiologists in The Netherlands via email asking their opinion about which parameters to use best with their corresponding cut-off points in HD unstable patients. The questionnaire included five cases of patients suffering blunt injuries. Additional information was presented after the first assessment in order to simulate the dynamic aspect of the evaluation of these patients. Physicians who were not part of their hospital's trauma team were excluded.

By asking the different physicians to make an assessment of the patient's hemodynamic situation (stable/unstable) a comparison of their judgment was made by calculating the Cohen's Kappa-value on agreement in and between these three groups. Cohen Kappa-value was defined as no agreement $<0$, none-to-slight agreement between 0.01 and 0.20 , fair agreement between 0.21 and 0.40 and general agreement with values over 0.41 . High intra-variability was defined if agreement was found between 35 and $65 \%$. All data was processed in an SPSS $22^{\circledR}$ database.

\section{Results}

\section{Review}

\section{Demographics}

Out of the 222 different papers identified, 67 were considered eligible for this study (see Fig. 1) [16-82]. Out of the final selection $52 \%$ described the diagnostic and/or treatment pathway of blunt abdominal injuries, $18 \%$ of pelvic injuries, $10 \%$ of vascular injuries, $10 \%$ of thoracic injuries, 
Fig. 1 HD stability search flowchart

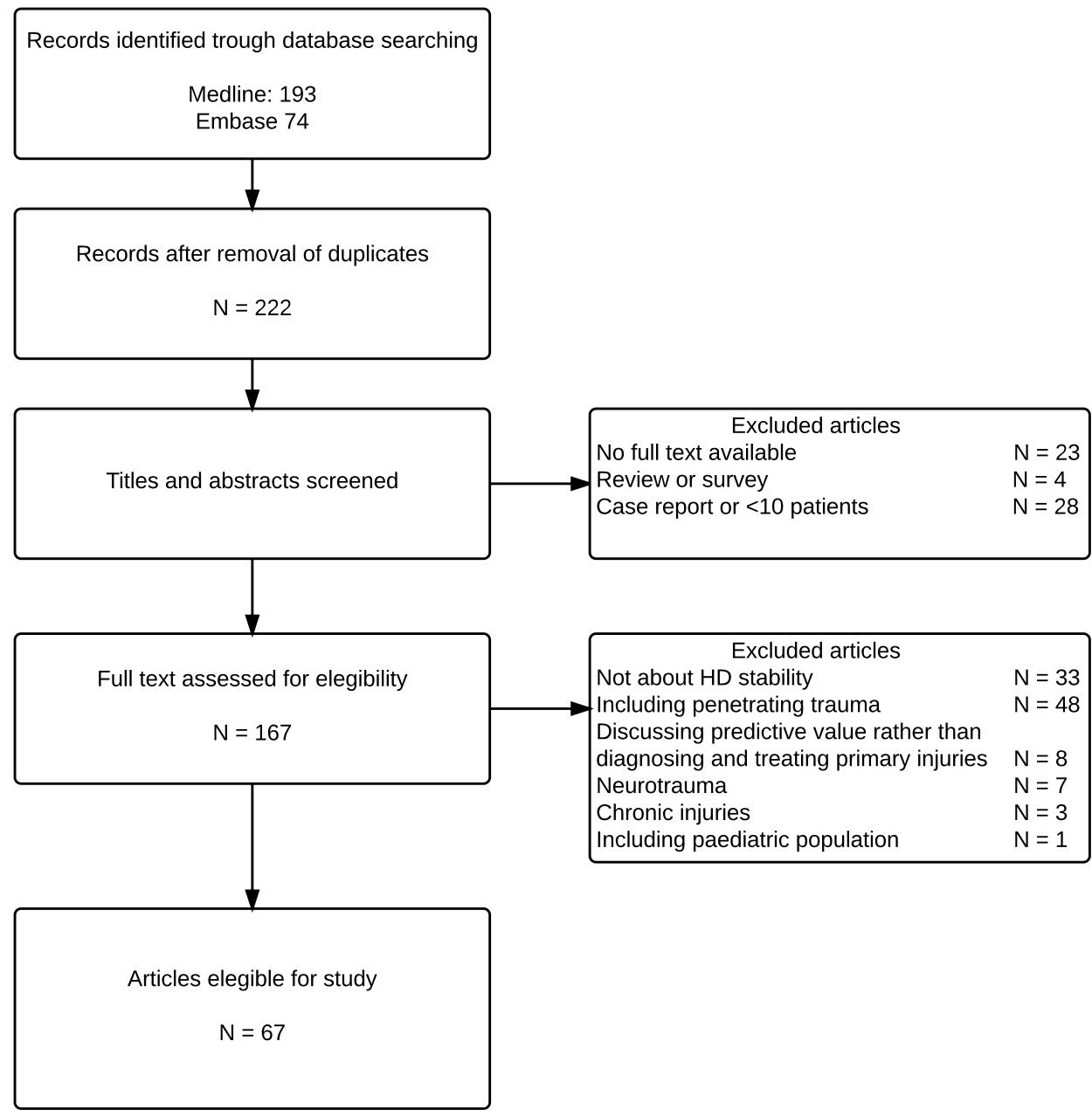

$1.5 \%$ injuries of the extremities and $8 \%$ injuries of blunt trauma patients in general.

\section{Definition of hemodynamic stability}

All studies acknowledged the term HD stability as a decisive factor in the management of blunt trauma patients [1682]. However, as shown in Table 1, different combinations of parameters are used in the assessment of HD stability. In $70 \%(47 / 67)$ of the studies HD stability was defined. The parameters were measured either at admission $(53 \%)$ or after resuscitation in the ED $(30 \%)$. The time of measurement or timing of resuscitation was not defined in $17 \%$.

\section{Parameters}

In total nine different parameters or combinations of parameters are used to define HD stability. The most used parameter is the SBP (53.2\%), measured either at admission $(52 \%)$ or after fluid resuscitation $(32 \%)$. The second most used parameter is a combination of SBP and HR
(29.8\%), measured either at admission (50\%) or after fluid resuscitation $(28.6 \%)$. Also SI was used in five occasions, either in combination with SBP or fluid resuscitation. No studies used HR alone to define HD stability. An overview of the used parameters for assessing HD stability is shown in Table 1.

\section{Cut-off points}

A wide range of cut-off points, meaning the moment when the physician interpreted the value as abnormal, is used (see Table 1). A blunt trauma patient was mainly defined as unstable if the SBP was below $90 \mathrm{mmHg}$ (range 70-100 $\mathrm{mmHg}$ ). 82\% used an SBP below $90 \mathrm{mmHg}$ as a marker for HD instability. A cut-off point for HR was defined by 14 articles and ranged from higher than 100 to higher than 130. HD instability was defined by a HR higher than $120 \mathrm{bpm}$ in $65 \%$, with $15 \%$ of the articles using the cutoff points of higher than $110 \mathrm{bpm}$ and higher than $100 \mathrm{bpm}$. The average cutoff point for SBP was below $91 \mathrm{mmHg}$ and the average cutoff point for HR higher than $116 \mathrm{bpm}$. 
Table 1 Top 5 used definitions of hemodynamic instability with corresponding cut-off points

\begin{tabular}{|c|c|c|c|c|c|}
\hline & Parameters & Cut-off points & Freq. & $\%$ of studies & References \\
\hline 1 & Only SBP & $<80-100 \mathrm{mmHg}$ at admission & 13 & 27.6 & {$[19,22,25,27,49,59,62,63,70,73,74,79,81]$} \\
\hline 2 & $\begin{array}{l}\text { SBP and } \\
\text { Response to } \\
\text { Fluid resuscitation } \\
\text { PRBC }\end{array}$ & $\begin{array}{l}<90 \mathrm{mmHg} \text { at admission } \\
\text { or after } \\
>1-2 \mathrm{~L} \text { initial fluids } \\
>2-6 \mathrm{PRBC} / 24 \mathrm{~h}\end{array}$ & 12 & 25.5 & {$[16,18,32,34,41,55,71,75]$} \\
\hline 3 & $\begin{array}{l}\text { SBP and } \\
\text { HR }\end{array}$ & $\begin{array}{l}<90 \mathrm{mmHg} \text { at admission } \\
>100-130 \mathrm{bpm} \text { at admission }\end{array}$ & 10 & 21.3 & {$[26,29,30,52,61,64,68,76,78,82]$} \\
\hline 4 & $\begin{array}{l}\text { SBP and } \\
\text { HR and } \\
\text { Response to } \\
\text { Fluid resuscitation }\end{array}$ & $\begin{array}{l}<90 \mathrm{mmHg} \text { at admission } \\
>100-120 \mathrm{bpm} \text { at admission or } \\
\text { after } \\
>1-21 \text { initial fluids }\end{array}$ & 4 & 8.5 & {$[33,40,67,80]$} \\
\hline \multirow[t]{2}{*}{5} & $\begin{array}{l}\text { SBP and } \\
\text { SI }\end{array}$ & $\begin{array}{l}<90 \mathrm{mmHg} \text { at admission } \\
>1 \text { at admission }\end{array}$ & 4 & 8.5 & {$[39,45,58,72]$} \\
\hline & Total & & 43 & 92 & $43 / 47$ \\
\hline
\end{tabular}

Top five used definitions of hemodynamic instability in the articles, organized by the different combinations of parameters with their range of corresponding cut-off points and percentage of articles using this definition

$H R$ heart rate, SBP systolic blood pressure, SI Shock Index (HF/SBP)

Another large variation in definition is whether these previously mentioned values were measured at admission or after resuscitation. 18 studies used fluid resuscitation as part of their definition, of which five authors did not define the amount of resuscitation. The amount of resuscitation was defined by either the used amount of crystalloids and/ or PRBC. The amount of crystalloids ranged between 1 and 2 1. The amount of PRBC given ranged between two and six units. The cut-off point for the SI was always 1.0.

\section{Survey amongst Dutch trauma team members (TTM)}

The response rate was $64 \%$ with an average completion time of $15 \mathrm{~min}$. A total of 251 responders completed the survey. $225(90 \%)$ of those were part of their hospital's trauma team. $36 \%$ were emergency physicians, $35 \%$ anesthesiologists and $29 \%$ trauma surgeons.

\section{Parameters}

When asked what specialists would consider the most important parameter, the three traditional vital signs (HR, sSBP and RR) as their most used parameters. HR was considered the most important by all TTM in 45\%, followed by the sSBP (30\%) and the RR (18\%). An overview of the most used parameters is shown in Table 2 . The least consensus about which parameters to use best is seen in the anesthesiologists group. The emergency physicians and trauma surgeon's groups show more consensus, with the latter group showing the biggest differences in percentages.

\section{Cut-off points}

The corresponding average cut-off points, differed between the different specialties. Purely based on the SBP, HR and RR with corresponding cut-off points, emergency physicians assess a trauma patient more early as potentially HD unstable, followed by trauma surgeons and anesthesiologists, respectively. An overview of the different cut-off points used for HD stability is shown in Table 3.

\section{Increasing heart rate}

All TTM will assess a patient with a higher heart rate more often as unstable. In the dynamic aspect of the survey, agreement is seen for all specialties when the HR is $98 \mathrm{bpm}$ with an average judgment of HD instability of $13 \%$. When the HR rises to $108 \mathrm{bpm}$, none-to-slight agreement is seen between the anesthesiologists (47\%) compared to trauma surgeons $(63 \%$ with $p=0.09)$ and emergency physicians (68\% with 0.015 ), where anesthesiologists are less likely to judge a patient as HD unstable. When the HR reaches $118 \mathrm{bpm}$ none-to-fair agreement is seen amongst all TTM specialists with emergency physicians (87\%) judging the patient as HD unstable the most and anesthesiologists (69\%) the least.

High intra-variability is seen amongst trauma surgeons (63\% unstable) and anesthesiologists (47\% unstable) when the HR reaches $108 \mathrm{bpm}$. No high intra-variability is seen amongst emergency physicians. 


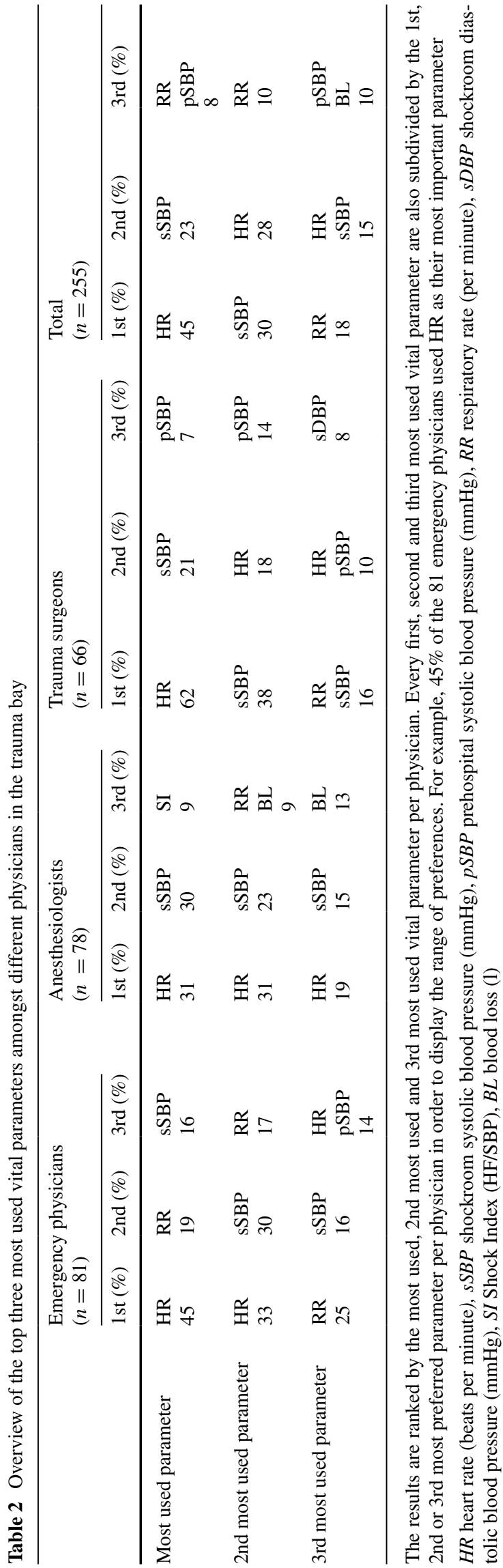

\section{Decreasing blood pressure}

Total consensus is reached when the $\mathrm{BP}$ of a young patient is $120 / 78 \mathrm{mmHg}$. When the BP drops to $105 / 67 \mathrm{mmHg}$ and $95 / 65 \mathrm{mmHg}$, none-to-fair agreement is seen between emergency physicians (30 and 77\%) compared to trauma surgeons (22\% with $p=0.404$ and $51 \%$ with $p=0.004$ ) and anesthesiologists (17\% with $p=0.104$ and $56 \%$ with $p=0.014)$, in which emergency physicians are more likely to judge a patient as HD unstable. No differences in agreement are found in young patients between trauma surgeons and anesthesiologists.

When the same parameters are tested in a 65 -year-old patient this changes. Elderly patients are more frequently assessed as unstable with the same blood pressure as a young patient for all specialties. When the BP of a 65 year old reaches $105 / 67 \mathrm{mmHg}$, anesthesiologists (31\%) will judge a patient as less HD unstable compared to trauma surgeons (39\% with $p=0.402)$ and emergency physicians (46\% with $p=0.096$ ). Agreement is seen between trauma surgeons and emergency physicians for the BP of 120/75 and $105 / 67 \mathrm{mmHg}$ ) of older patients.

High intra-variability is seen for the BP of a young patients amongst trauma surgeons (51\% unstable) and anesthesiologists (56\% unstable) when the BP reaches $95 / 65 \mathrm{mmHg}$. In older patients high intra-variability is seen amongst emergency physicians (46\% unstable) and trauma surgeons (39\%) when the BP reaches 105/67 mmHg.

\section{Negative versus positive FAST}

None-to-slight agreement is shown between trauma surgeons and the other TTM specialists with a positive result of the FAST. When the FAST shows any fluid around organs or free fluid in the abdomen, trauma surgeons (27 and 29\%, respectively) are significantly less likely to judge a patient as HD unstable compared to baseline parameters than anesthesiologists (43\% with $p=0.095$ and $53 \%$ with $p=0.011$, respectively) and emergency physicians (44\% with $p=0.077$ and $55 \%$ with $p=0.007$ ). There are no significant differences between anesthesiologists and emergency physicians.

High intra-variability is seen amongst anesthesiologists and emergency physicians when the FAST shows either free fluid around a solid organ (43 and 44\% unstable, respectively) or free abdominal fluid (53 and 55\% unstable, respectively). No high intra-variability is seen amongst trauma surgeons.

\section{Decreasing hemoglobin level}

There is none-to-slight agreement between trauma surgeons and the other two specialties about the use of low hemoglobin $(\mathrm{Hb})$ levels upon arrival in the trauma bay when the 
Table 3 Overview of top three most used parameters with their corresponding cut-off points used by Dutch trauma team members

\begin{tabular}{|c|c|c|c|c|c|c|c|c|c|}
\hline \multirow[t]{2}{*}{ Parameter } & \multirow[t]{2}{*}{ Cut-off point } & \multicolumn{2}{|c|}{ Emergency physicians } & \multicolumn{2}{|c|}{ Anesthesiologists } & \multicolumn{2}{|c|}{ Trauma surgeons } & \multicolumn{2}{|c|}{ Total $(n=85)$} \\
\hline & & $\begin{array}{l}\text { pSBP } \\
(n=42)\end{array}$ & $\begin{array}{l}\text { sSBP } \\
(n=61)\end{array}$ & $\begin{array}{l}\mathrm{P} \\
=23)\end{array}$ & $\begin{array}{l}\text { sSBP } \\
(n=51)\end{array}$ & $\begin{array}{l}\text { pSBP } \\
(n=20)\end{array}$ & $\begin{array}{l}\text { sSBP } \\
(n=44)\end{array}$ & $\mathrm{pSBP}$ & sSBP \\
\hline \multirow[t]{5}{*}{$\mathrm{SBP}(\mathrm{mmHg})$} & $<110-105$ & $7 \%$ & $9 \%$ & & $2 \%$ & $5 \%$ & $5 \%$ & $6 \%$ & $5 \%$ \\
\hline & $<100-95$ & $59 \%$ & $52 \%$ & & $39 \%$ & $55 \%$ & $41 \%$ & $56 \%$ & $45 \%$ \\
\hline & $<90-85$ & $23 \%$ & $34 \%$ & & $37 \%$ & $25 \%$ & $43 \%$ & $26 \%$ & $38 \%$ \\
\hline & $<80$ & $10 \%$ & $7 \%$ & & $22 \%$ & $15 \%$ & $11 \%$ & $13 \%$ & $13 \%$ \\
\hline & $\begin{array}{l}\text { Avg. } \\
\text { (mmHg) }\end{array}$ & $<96$ & $<95$ & & $<91$ & $<94$ & $<94$ & $<95$ & $<94$ \\
\hline Parameter & Cut-off point & \multicolumn{2}{|c|}{ Emergency physicians $(n=66)$} & \multicolumn{2}{|c|}{ Anesthesiologists $(n=56)$} & \multicolumn{2}{|c|}{ Trauma surgeons $(n=52)$} & \multicolumn{2}{|c|}{ Total $(n=174)$} \\
\hline \multirow[t]{5}{*}{ HR (bpm) } & $>90-95$ & \multicolumn{2}{|l|}{$3 \%$} & \multicolumn{2}{|c|}{$2 \%$} & \multicolumn{2}{|l|}{$6 \%$} & \multicolumn{2}{|l|}{$4 \%$} \\
\hline & $>100-105$ & \multicolumn{2}{|l|}{$75 \%$} & \multicolumn{2}{|l|}{$40 \%$} & \multicolumn{2}{|l|}{$50 \%$} & \multicolumn{2}{|l|}{$55 \%$} \\
\hline & $>110-115$ & \multicolumn{2}{|l|}{$15 \%$} & \multicolumn{2}{|l|}{$21 \%$} & \multicolumn{2}{|l|}{$23 \%$} & \multicolumn{2}{|l|}{$19 \%$} \\
\hline & $>120$ & \multicolumn{2}{|l|}{$8 \%$} & \multicolumn{2}{|c|}{$38 \%$} & \multicolumn{2}{|l|}{$29 \%$} & \multicolumn{2}{|l|}{$22 \%$} \\
\hline & Avg. (bpm) & \multicolumn{2}{|l|}{$>103$} & \multicolumn{2}{|c|}{$>110$} & \multicolumn{2}{|l|}{$>107$} & \multicolumn{2}{|l|}{$>106$} \\
\hline Parameter & Cut-off point & \multicolumn{2}{|c|}{ Emergency physicians $(n=56)$} & \multicolumn{2}{|c|}{ Anesthesiologists $(n=39)$} & \multicolumn{2}{|c|}{ Trauma surgeons $(n=22)$} & Total ( & $=117)$ \\
\hline $\mathrm{RR}(\mathrm{p} / \mathrm{m})$ & $<40-35$ & $4 \%$ & & $18 \%$ & & $23 \%$ & & $14 \%$ & \\
\hline & $<30-25$ & $63 \%$ & & $59 \%$ & & $50 \%$ & & $59 \%$ & \\
\hline & $<20-15$ & $31 \%$ & & $23 \%$ & & $27 \%$ & & $27 \%$ & \\
\hline & Avg. (p/m) & $<34$ & & $<33$ & & $<33$ & & $<34$ & \\
\hline
\end{tabular}

$H R$ heart rate (beats per minute), $S B P$ systolic blood pressure (mmHg), $R R$ respiratory rate (per minute), $p S B P$ prehospital systolic blood pressure $(\mathrm{mmHg}), s S B P$ shockroom systolic blood pressure $(\mathrm{mmHg})$

$\mathrm{Hb}$ levels are 7.2, 6.2 and $5.2 \mathrm{mmol} / \mathrm{l}$. Trauma surgeons are significantly less likely to be influenced by the level of $\mathrm{Hb}$ in their decision making of HD instability compared to emergency physicians and anesthesiologists. Trauma surgeons are significantly less likely to judge a patient as HD unstable when $\mathrm{Hb}$ levels are 6.2 or $5.2 \mathrm{mmol} / \mathrm{l}$ in male patients compared to anesthesiologists ( $p=0.009$ and 0.014$)$ and emergency physicians $(p=0.028$ and 0.009$)$. This also accounts for $\mathrm{Hb}$ levels of 6.2 and $5.2 \mathrm{mmol} / \mathrm{l}$ in female patients ( $p=0.03$ for anesthesiologists and $p=0.001$ for emergency physicians). The only time where there is no agreement between anesthesiologists and emergency physicians is when the $\mathrm{Hb}$ levels of females reach $5.2 \mathrm{mmol} / \mathrm{l}$.

High intra-variability is seen amongst emergency physicians when the HB levels are $6.2 \mathrm{mmol} / \mathrm{l}$ in male $(51 \%$ unstable) and females (44\% unstable) patients. This is also seen amongst anesthesiologists with 51 and 55\% unstable for the same HB levels for males and females, respectively. High intra-variability is seen amongst trauma surgeons when the HB levels reaches $5.2 \mathrm{mmol} / \mathrm{l}$ in male $(51 \%$ unstable) and female (53\% unstable) patients.

\section{Shock Index (SI)}

The influence of Shock Index on the HD assessment in the Dutch emergency bay is low, with only 42 TTM defining a cut-off point for SI, with an average cut-off point of higher than 1.0.

\section{Resuscitation}

TTM $(n=40)$ on average will judge a patient as HD unstable when five or more units of packed red blood cells (PRBC) are infused with response.

\section{Comparison of literature versus practice}

As the review of the literature showed that the SBP, used in $53 \%$ of the definitions, measured either at admission before or after fluid resuscitation, was considered the most important parameter. No study defined HD stability purely based on the HR. A combination of SBP and HR, before or after resuscitation, was used in about $30 \%$ of the cases. Different cut-off points are used for the different parameters measured before or after different amounts of fluid resuscitation. The average cutoff point for SBP was below $91 \mathrm{mmHg}$ and for HR higher than $116 \mathrm{bpm}$.

The survey showed that HR is considered the most important parameter for the assessment of HD stability by Dutch TTM in $45 \%$, followed by SBP and RR. The average cutoff point for HR was higher than $106 \mathrm{bpm}$, for SBP below $95 \mathrm{mmHg}$. 


\section{Discussion}

During the early assessment, the trauma team needs to triage blunt trauma patients according to their HD status in order to choose the best treatment pathway determined by evidence-based research. With multiple specialties featuring in current trauma teams, a multidisciplinary approach will only benefit the treatment of a trauma patient if the interdisciplinary differences in language are settled, especially in moments when time is scarce. Our systematic review and analyses of a survey amongst Dutch TTM has showed that there is a lack of consensus about which parameters and their corresponding cut-off points to use for the judgement of HD instability. If a definition of HD instability is even given in the literature, there are clear differences in the used parameters and corresponding cut-off points. There is high inter- and intra-variability between and amongst the different specialties featuring in their trauma team. This study also shows differences in parameters used for HD stability definition between current literature and TTM in The Netherlands.

To create a uniform language, research is performed to create consensus-based guidelines with clear treatment paths for blunt trauma patients. The lack of consensus about parameters and cut-off points in literature could create difficulties in making population-based conclusions for the evidence-based practice since study groups in literature are not fully comparable.

In the attempt to make uniform policy within the trauma team consisting of a trauma surgeon, anesthesiologist and emergency physician, the evaluation of trauma patients in the Dutch emergency ward is organized according to the ATLS principles. The ATLS guideline uses the term hemorrhagic shock (often used as alternative for hemodynamic instability) based on the percentage or amount of blood loss, which would correspond with a certain increase of $\mathrm{HR}, \mathrm{RR}$ and a certain decrease in SBP, urinary output and Glasgow Coma Scale. The validity of this classification is, however, under debate [7]. An online survey conducted by Mutschler et al. amongst 383 ATLS course directors and instructors confirms the doubts over the ATLS classification of shock. They showed that although the "A, B, C, D, E" approach is widely implemented, the general opinion is that only a limited number of patients can be classified by the current ATLS classification of shock. Furthermore, only $10.9 \%$ considered the ATLS classification of hypovolemic shock as a 'good guide' for fluid resuscitation and blood product transfusion, whereas $45.1 \%$ stated that this classification only 'may help' or has 'no impact' to guide resuscitation strategies [83].

Bland et al. already showed the difficulties in judging the HD status of critically ill patients back in 1985. They state that traditional abnormal vital parameters might not be sufficient to define HD instability. They state that even when vital signs are normal, some patients can have concealed deficiencies in tissue oxygenation [84].

Up till today HD stability is based on clinical gestalt. Clinical gestalt by itself is known to be a poor predictor for massive transfusion, or death in trauma patients, with sensitivity as low as $66 \%$ [85]. Several scoring systems have been developed to create a uniform definition for HD instability based on hemodynamic parameters and their ability to predict mortality or massive transfusion.

Meredith et al. devised the first scoring system, 'Hemodynamic Instability Score' (HIS), in 1994 to aid management of blunt hepatic trauma because of the large portion of unnecessary laparotomies. The scoring system was based on hypotension defined as SBP below $100 \mathrm{mmHg}$ and response to initial resuscitation and need for ongoing fluid resuscitation [86]. Moore et al. [87] noted that continuing considerable variability in the definitions of HD instability and the lack of a validated scoring system. They modified the HIS by changing the cut-off point of SBP to lesser than $90 \mathrm{mmHg}$, adding tachycardia as greater than $130 \mathrm{bpm}$ and response to initial advanced trauma life support recommended volume loading and the need for ongoing resuscitation including PRBC transfusion. This classification is, however, still to be validated in prospective studies.

Other, more recent, scoring systems for prediction of massive transfusion (MT), which partly includes prediction of persistent hemodynamic instability, such as the TASH [88], ABC [89] and the revised MTS score [90] use similar, or include more hemodynamic parameters as the parameters used in the HIS score. The TASH score weighs different hemodynamic parameters with several laboratory values, whereas the ABC score relies purely on hemodynamic parameters and the outcome of the FAST-echo. The revised MTS score uses only SBP as a vital parameter combined with temperature and several laboratory values based on the triangle of death in trauma patients (hypothermia, coagulopathy and metabolic acidosis).

Brockamp et al. reviewed several of these scoring systems, including the TASH and the ABC. The results, interestingly enough, showed that the only two scoring systems (TASH and PWH/Rainer) that used base deficit (BD) as a surrogate for hypoperfusion, showed the highest overall accuracy in predicting ongoing hemorrhage and MT [91].

Another study by Mutschler et al. [92], suggests the usefulness of $\mathrm{BD}$ in the $\mathrm{ED}$. Based on a retrospective study that included over 16,000 patients from the Trauma Register $\mathrm{DGU}^{\circledR}$, they proposed a shock classification based on the levels of BD on ED admission. The found that their four proposed classes of worsening of BD seems to predict transfusion requirements and mortality more significantly more accurate than the current groups in the ATLS classification. BD might be a relevant clinical approach to early risk-stratify 
severely injured patients in the state of hypovolemic shock and for blood product transfusion during initial assessment.

As mentioned before SI has been developed and an abnormal SI values have showed to be a better predictor for transfusion and mortality in trauma patients than the vital signs apart [11, 13-15]. Recently Joseph et al. describe a DSI (SI-ER-SI-Field) in which they showed that a positive delta SI (DSI) is a better predictor for mortality (13.3\%) in trauma patients compared to mortality when patients have a normal/negative DSI $(9.6 \%)$. They conclude that a DSI $>0.1$ is associated with a higher chance of death (hazard ratio $[95 \% \mathrm{CI}]=1.36[1.29-1.45]$ ) [93].

As the higher prediction of mortality by the decreasing SI over time showed, it is important to realize that HD instability is difficult to assess based on a single point measurement. Clinical guidelines that use development of the vital signs over a period of time to suggest a condition of HD instability will be the more preferred option, since the effects of resuscitation will also have to be awaited.

Which baseline parameters should be used define HD instability remains a point of debate. Many articles have been published describing hemodynamic parameters and their ability to predict mortality. When reviewing several HD scoring systems in combination with our literature search, a possible modification should be proposed by adding instability measured by combination of the change in SBP and HR from the field into the ER, calculated as the DSI. Another option is to add hemoglobin levels as some authors suggest or use the indicative value of hemoglobin level at admission, a drop of hemoglobin in the emergency bay after volume therapy or inadequate increase of hemoglobin after PRBC transfusion. Also base excess should be implemented in this system as proposed by Mutschler et al. [92]. The lack of consensus about the consequences of a positive FAST on the judgement of the HD status of the patient makes that this item should be left out of a scoring system, although the FAST is a vital part in the trauma screening. This modified HD scoring system should be easy to calculate and time to obtain results should be kept to a minimum in order to quickly establish the HD status of the trauma patient. It is important to realize that these systems are indicative and will only indicate a patient at risk for HD instability. With the current lack of consensus as this study shows and with the heterogeneity of the trauma patient population, combined with the low sensitivity of the clinical gestalt, a valid scoring system should be to focus of future guidelines.

\section{Conclusion}

Based on this review of the literature, it is clear that HD stability is acknowledged as a vital part in the management of blunt trauma patients. However, different parameters and cut-off points are used in literature and daily practice. The interpretation of the circulatory status is highly variable and depends the author's personal choices. The same accounts for Dutch TTM. There are structural differences within and between the different physicians participating in their hospital's trauma team in the assessment of the HD stability. We can conclude that the term HD stability is used without full general consensus. A trauma team ready to cooperate with consensus-based opinions and a clear definition of HD stability together with a valid scoring system is in our opinion the best method to assess and treat seriously injured trauma patients.

\section{Compliance with ethical standards}

Conflict of interest Loggers, S.A.I. declares that he has no conflict of interest. Koedam, T. declares that he has no conflict of interest. Giannakopoulos, G.F. declares that he has no conflict of interest. Vandewalle, E. declares that he has no conflict of interest. Erwteman, E. declares that he has no conflict of interest. Zuidema, W.P. declares that he has no conflict of interest.

Ethical approval All procedures performed in studies involving human participants were in accordance with the ethical standards of the institutional and/or national research committee and with the 1964 Helsinki declaration and its later amendments or comparable ethical standards. For this type of study formal consent is not required.

Informed consent Informed consent was obtained from all individual participants included in the study.

Open Access This article is distributed under the terms of the Creative Commons Attribution 4.0 International License (http://creativecommons.org/licenses/by/4.0/), which permits unrestricted use, distribution, and reproduction in any medium, provided you give appropriate credit to the original author(s) and the source, provide a link to the Creative Commons license, and indicate if changes were made.

\section{References}

1. World Health Organization. Causes of death 2008 summary tables, Department, Health statistics and informatics. World Health Organization, Geneva, Switzerland; 2011. http://www. who.int/evidence/bod. Accessed 22 Mar 2016.

2. World Health Organization. Global Burden of disease 2004 update, Health statistics and informatics. World Health Organization, Geneva, Switzerland, 2011. http://www.who.int/healthinfo/global_burden_disease/GBD_report_2004update_full.pdf. Accessed 22 Mar 2016.

3. American College of Surgeons. Advanced trauma life support for doctors. 8th ed. Chicago: American College of Surgeons; 2008.

4. Gaarder C, et al. Scandinavian guidelines - the massive bleeding patient. Scand J Surg. 2008;97:15-36.

5. Johansson PI, et al. Effect of haemostatic control resuscitation on mortality in massively bleeding patients: a before and after study. Vox Sang. 2009;96:111-8. 
6. American College of Surgeons. Prehospital Trauma Life Support. 7th ed. St. Louis: Elsevier; 2011.

7. Guly HR, Bouamra O, Little R, Dark P, Coats T, Lecky FE, et al. Testing the validity of the ATLS classification of hypovolaemic shock. Resuscitation. 2010;81:1142-7.

8. Little RA, Kirkman E, Driscoll P, Hanson J, Mackway-Jones K. Preventable deaths after injury: why are the traditional 'vital' signs poor indicators of blood loss? J Accid Emerg Med. 1995;12:1-14.

9. Victorino GP, Battistella FD, Wisner DH. Does tachycardia correlate with hypotension after trauma? J Am Coll Surg. 2003;196:679-84.

10. Brasel KJ, Guse C, Gentilello LM, Nirula R. Heart rate: is it truly a vital sign? J Trauma. 2007;62:812-7.

11. Rady MY, Smithline HA, Blake H, Nowak R, Rivers E. A comparison of the shock index and conventional vital signs to identify acute, critical illness in the emergency department. Ann Emerg Med. 1994;24:685-90.

12. Luna GK, Eddy AC, Copass M. The sensitivity of vital signs in identifying major thoracoabdominal hemorrhage. Am J Surg. 1989;157:512-5

13. Birkhahn RH, Gaeta TJ, Terry D, Bove JJ, Tloczkowski J. Shock index in diagnosing early acute hypovolemia. Am J Emerg Med. 2005;23(3):323-6.

14. Vandromme MJ, Griffin RL, Kerby JD, McGwin G, Rue LW, Weinberg JA. Identifying risk for massive transfusion in the relatively normotensive patient: utility of the prehospital shock index. J Trauma. 2011;70:384-8.

15. Cannon CM, Braxton CC, Kling-Smith M, Mahnken JD, Carlton $\mathrm{E}$, Moncure M. Utility of the shock index in predicting mortality in traumatically injured patients. J Trauma. 2009;67:1426-30.

16. Ogura T, Lefor AT, Nakano M, Izawa Y, Morita H. Nonoperative management of hemodynamically unstable abdominal trauma patients with angioembolization and resuscitative endovascular balloon occlusion of the aorta. J Trauma Acute Care Surg. 2015;78(1):132-5.

17. Iqbal Y, Taj MN, Ahmed A, Rehman ZU, Akbar Z. Validity of the fast scan for diagnosis of intraabdominal injury in blunt abdominal trauma. J Ayub Med Coll Abbottabad. 2014;26(1):52-6.

18. Li M, Yu WK, Wang XB, Ji W, Li JS, Li N. Non-operative management of isolated liver trauma. Hepatobiliary Pancreat Dis Int. 2014;13(5):545-50.

19. Olthof DC, Luitse JS, de Rooij PP, Leenen LP, Wendt KW, Bloemers FW, Goslings JC. Variation in treatment of blunt splenic injury in Dutch academic trauma centers. J Surg Res. 2015;194(1):233-8.

20. Asfar S, Khoursheed M, Al-Saleh M, Alfawaz AA, Farghaly MM, Nur AM, Liver Trauma Registry Group. Management of liver trauma in Kuwait. Med Princ Pract. 2014;23(2):160-6.

21. Toth L, King KL, McGrath B, Balogh ZJ. Factors associated with pelvic fracture-related arterial bleeding during trauma resuscitation: a prospective clinical study. J Orthop Trauma. 2014;28(9):489-95.

22. Katsura M, Yamazaki S, Fukuma S, Matsushima K, Yamashiro T, Fukuhara S. Comparison between laparotomy first versus angiographic embolization first in patients with pelvic fracture and hemoperitoneum: a nationwide observational study from the Japan Trauma Data Bank. Scand J Trauma Resusc Emerg Med. 2013;3(21):82.

23. Figler BD, Malaeb BS, Voelzke B, Smith T, Wessells H. External validation of a substratification of the American Association for the Surgery of Trauma renal injury scale for grade 4 injuries. J Am Coll Surg. 2013;217(5):924-8.

24. van der Wilden GM, Velmahos GC, Joseph DK, Jacobs L, Debusk MG. Successful nonoperative management of the most severe blunt renal injuries: a multicenter study of the research consortium of New England Centers for Trauma. JAMA Surg. 2013;148(10):924-31.

25. Huber-Wagner $S$, Biberthaler $P$, Häberle $S$, Wierer $M$, Dobritz M, Rummeny E, van Griensven M, Kanz KG, Lefering R, TraumaRegister DGU. Whole-body CT in haemodynamically unstable severely injured patients-a retrospective, multicentre study. PLoS One. 2013;8(7):e68880.

26. Bar-Or D, Salottolo KM, Orlando A, Mains CW, Bourg P, Offner PJ. Association between a geriatric trauma resuscitation protocol using venous lactate measurements and early trauma surgeon involvement and mortality risk. J Am Geriatr Soc. 2013;61(8):1358-64.

27. Purvis D, Aldaghlas T, Trickey AW, Rizzo A, Sikdar S. A novel decision tree approach based on transcranial doppler sonography to screen for blunt cervical vascular injuries. J Ultrasound Med. 2013;32:1023-31.

28. Di Eusanio M, Folesani G, Berretta P, Petridis FD, Pantaleo A, Di Bartolomeo R, et al. Delayed management of blunt traumatic aortic injury: open surgical versus endovascular repair. Ann Thorac Surg. 2013;95:1591-7.

29. Olthof DC, Sierink JC, van Delden OM, Luitse JSK, Goslings JC. Time to intervention in patients with splenic injury in a Dutch level 1 trauma centre. Inj Int J Care Inj. 2014;45:95-100.

30. Myint KS, French S, Williams-Johnson J, Williams E, Johnson P, Reid MO, Gordon-Strachan G. Role of routine chest radiographs in the evaluation of patients with stable blunt chest trauma-a prospective analysis. West Indian Med J. 2012;61(1):64-72.

31. van der Wilden GM, Velmahos GC, Joseph AK, Jacobs L, DeBusk MG, de Moya MA, et al. Successful nonoperative management of the most severe blunt renal injuries. JAMA Surg. 2013;148(10):924-31.

32. Yuan KC, Wong YC, Lin BC, Kang SC, Liu EH, Hsu YP. Negative catheter angiography after vascular contrast extravasations on computed tomography in blunt torso trauma: an experience review of a clinical dilemma. Scand J Trauma Resusc Emerg Med. 2012;7(20):46.

33. Bhullar IS, Frykberg ER, Siragusa D, Chesire D, Paul J, Kerwin $\mathrm{AJ}$, et al. Selective angio graphic embolization of blunt splenic traumatic injuries in adults decreases failure rate of nonoperative management. J Trauma. 2012;72(5):1127-34.

34. Fu CY, Hsieh $\mathrm{CH}$, Shih $\mathrm{CH}$, Wang YC, Chen RJ, Huang HC, Huang JC, Wu SC, Tsuo HC, Tung HJ. Selective computed tomography and angioembolization provide benefits in the management of patients with concomitant unstable hemodynamics and negative sonography results. World J Surg. 2012;36(4):819-25.

35. Barleben A, Jafari F, Rose J, Dolich M, Malinoski D, Cinat M, et al. Implementation of a cost-saving algorithm for pelvic radiographs in blunt trauma patients. J Trauma. 2011;71(3):582-4.

36. Kawahito $\mathrm{K}$, Adachi $\mathrm{H}$. Hypothermic circulatory arrest for acute traumatic aortic rupture associated with shock. Gen Thorac Cardiovasc Surg. 2011;59(7):472-6.

37. van der Vlies CH, Olthof DC, van Delden OM, Ponsen KJ, de la Rosette JJMCH, Goslings JC, et al. Management of blunt renal injury in a level 1 trauma centre in view of the European guidelines. Inj Int J Care Inj. 2012;43:1816-20.

38. Tan ECTH, van Stigt SFL, van Vugt AB. Effect of a new pelvic stabilizer (T-POD1) on reduction of pelvic volume and haemodynamic stability in unstable pelvic fractures. Inj Int J Care Inj. 2010;41:1239-43.

39. Franco F, Monaco D, Volpi A, Marcato C, Larini P, Rossi C. The role of arterial embolization in blunt splenic injury. Radiol Med. 2011;116(3):454-65.

40. Matsumoto S, Sekine K, Yamazaki M, Sasao K, Funabiki T, Shimizu M, Yoshii H, Kishikawa M, Kitano M. Predictive value of a flat inferior vena cava on initial computed tomography for 
hemodynamic deterioration in patients with blunt torso trauma. $\mathrm{J}$ Trauma. 2010;69(6):1398-402.

41. Wang YC, Fu CY, Chen YF, Hsieh CH, Wu SC, Yeh CC. Role of arterial embolization on blunt hepatic trauma patients with type I contrast extravasation. Am J Emerg Med. 2011;29:1147-51.

42. Ball CG, Wyrzykowski AD, Kirkpatrick AW, Dente CJ, Nicholas JM, Salomone JP, Rozycki GS, Kortbeek JB, Feliciano DV. Thoracic needle decompression for tension pneumothorax: clinical correlation with catheter length. Can J Surg. 2010;53(3):184-8.

43. DuBose J, Inaba K, Barmparas G, Teixeira PG, Schnüriger B, Talving P, Salim A, Demetriades D. Bilateral internal iliac artery ligation as a damage control approach in massive retroperitoneal bleeding after pelvic fracture. J Trauma. 2010;69(6):1507-14.

44. Tan KK, Yan ZY, Vijayan A, Chiu MT. Management of diaphragmatic rupture from blunt trauma. Singap Med J. 2009;50(12):1150-3.

45. Morozumi J, Homma H, Ohta S, Noda M, Oda J, Yukioka T, et al. Impact of mobile angiography in the emergency department for controlling pelvic fracture hemorrhage with hemodynamic instability. J Trauma. 2010;68(1):90-5.

46. Shirazi M, Sefidbakht S, Jahanabadi Z, Asadolahpour A, Afrasiabi MA. Is early reimaging CT scan necessary in patients with grades III and IV renal trauma under conservative treatment? J Trauma. 2010;68(1):9-12.

47. Tan KK, Chan DX, Vijayan A, Chiu MT. Management of pancreatic injuries after blunt abdominal trauma. Experience at a single institution. JOP. 2009;10(6):657-63.

48. Misselbeck TS, Teicher EJ, Cipolle MD, Pasquale MD, Shah KT, Badellino MM, et al. Hepatic angioembolization in trauma patients: indications and complications. J Trauma. 2009;67(4):769-73

49. Fu CY, Wu SC, Chen RJ, Wang YC, Chung PK, Huang HC, et al. Evaluation of pelvic fracture stability and the need for angioembolization: pelvic instabilities on plain film have an increased probability of requiring angioembolization. Am J Emerg Med. 2009;27:792-6.

50. Ball CG, Rozycki GS, Feliciano DV. Upper extremity amputations after motor vehicle rollovers. J Trauma. 2009;67(2):410-2.

51. Pata G, Casella C, Di Betta E, Grazioli L, Salerni B. Extension of nonoperative management of blunt pancreatic trauma to include grade III injuries: a safety analysis. World J Surg. 2009;33:1611-7.

52. Giannopoulos GA, Katsoulis IE, Tzanakis NE, Patsaouras PA, Digalakis MK. Non-operative management of blunt abdominal trauma. Is it safe and feasible in a district general hospital? Scand J Trauma Resusc Emerg Med. 2009;17:22.

53. Geisbüsch P, Leszczynsky M, Kotelis D, Hyhlik-Dürr A, Weber TF, Böckler D. Open versus endovascular repair of acute aortic transections-a non-randomized single-center analysis. Langenbecks Arch Surg. 2009;394:1101-7.

54. Gauer JM, Gerber-Paulet S, Seiler C, Schweizer WP. Twenty years of splenic preservation in trauma: lower early infection rate than in splenectomy. World J Surg. 2008;32(12):2730-5.

55. Verbeek D, Sugrue M, Balogh Z, Cass D, Civil I, Wills V, et al. Acute management of hemodynamically unstable pelvic trauma patients: time for a change? World J Surg. 2008;32:1874-82.

56. Monnin V, Sengel C, Thony F, Bricault I, Voirin D, Ferretti $\mathrm{G}$, et al. Place of arterial embolization in severe blunt hepatic trauma: a multidisciplinary approach. Cardiovasc Interv Radiol. 2008;31:875-82.

57. Bala M, Edden Y, Mintz Y, Kisselgoff D, Gercenstein I, Almogy $\mathrm{G}$, et al. Blunt splenic trauma: predictors for successful nonoperative management. IMAJ. 2007;9:857-61.

58. Lin WC, Chen YF, Lin CH, Tzeng YH, Chiang HJ, Ho YJ, Shen WC, Chen JH. Emergent transcatheter arterial embolization in hemodynamically unstable patients with blunt splenic injury. Acad Radiol. 2008;15(2):201-8.

59. Friese RS, Malekzadeh S, Shafi S, Gentilello LM, Starr A. Abdominal ultrasound is an unreliable modality for the detection of hemoperitoneum in patients with pelvic fracture. J Trauma. 2007;63(1):97-102.

60. Kuncir EJ, Velmahos GC. Diagnostic peritoneal aspiration-the foster child of DPL: a prospective observational study. Int J Surg. 2007;5(3):167-71 (Epub 2006 Aug 14).

61. Tötterman A, Madsen JE, Skaga NO, Røise O. Extraperitoneal pelvic packing: a salvage procedure to control massive traumatic pelvic hemorrhage. J Trauma. 2007;62(4):843-52.

62. Zheng YX, Chen L, Tao SF, Song P, Xu SM. Diagnosis and management of colonic injuries following blunt trauma. World J Gastroenterol. 2007;13(4):633-6.

63. Cook J, Salerno C, Krishnadasan B, Nicholls S, Meissner M, Karmy-Jones R. The effect of changing presentation and management on the outcome of blunt rupture of the thoracic aorta. J Thorac Cardiovasc Surg. 2006;131(3):594-600.

64. Gezen FC, Cinçin TG, Oncel M, Vural S, Erdemir A, Dalkiliç G, Menteş C, Tüzün B. Noninvasive management strategy in hemodynamically unstable patients with blunt trauma. Ulus Travma Acil Cerrahi Derg. 2006;12(1):43-50.

65. Fang JF, Wong YC, Lin BC, Hsu YP, Chen MF. Usefulness of multidetector computed tomography for the initial assessment of blunt abdominal trauma patients. World J Surg. 2006;30:176-82.

66. Stampfl P, Greitbauer M, Zimpfer D, Fleck T, Schoder M, Czerny M, et al. Mid-term results of conservative, conventional and endovascular treatment for acute traumatic aortic lesions. Eur J Vasc Endovasc Surg. 2006;31:475-80.

67. Christmas AB, Wilson AK, Manning B, Franklin GA, Miller FB, Rodriguez JL, et al. Selective management of blunt hepatic injuries including nonoperative management is a safe and effective strategy. Surgery. 2005;138(4):606-11.

68. Peitzman AB, Harbrecht BG, Rivera L, Heil B, The Eastern Association for the Surgery of Trauma Multi institutional Trials Workgroup. Failure of observation of blunt splenic injury in adults: variability in practice and adverse consequences. J Am Coll Surg. 2005;201(2):179-87.

69. Balogh Z, Caldwell E, Heetveld M, D'Amours S, Schlaphoff G, Sugrue M, et al. Institutional practice guidelines on management of pelvic fracture-related hemodynamic instability: do they make a difference? J Trauma. 2005;58(4):778-82.

70. Kataoka Y, Maekawa K, Nishimaki H, Yamamoto S, Soma K. Iliac vein injuries in hemodynamically unstable patients with pelvic fracture caused by blunt trauma. J Trauma. 2005;58(4):704-8 discussion 708-10.

71. Mitsuhide K, Junichi S, Atsushi N, Masakazu D, Shinobu H, Hiroshi Y. Computed tomographic scanning and selective laparoscopy in the diagnosis of blunt bowel injury: a prospective study. J Trauma. 2005;58(4):696-703.

72. Hagiwara A, Fukushima H, Murata A, Matsuda H, Shimazaki S. Blunt splenic injury: usefulness of transcatheter arterial embolization in patients with a transient response to fluid resuscitation. Radiology. 2005;235(1):57-64.

73. Suzuki T, Moirmura N, Kawai K, Sugiyama M. Arterial injury associated with acute compartment syndrome of the thigh following blunt trauma. Injury. 2005;36(1):151-9.

74. Smithson L, Morrell J, Kowalik U, Flynn W, Guo WA. Correlation of computed tomographic signs of hypoperfusion and clinical hypoperfusion in adult blunt traumaJournal of Trauma and Acute Care Surgery. 2015;78(6):1162-7.

75. Fu CY, Yang SJ, Liao CH, Lin BC, Kang SC, Wang SY, Yuan $\mathrm{KC}$, Ouyang $\mathrm{CH}$, Hsu YP. Hypotension does not always make computed tomography scans unfeasible in the management of blunt abdominal trauma patients. Injury. 2015;46(1):29-34. 
76. Tugnoli G, Bianchi E, Biscardi A, Coniglio C, Isceri S, Simonetti L, Gordini G, Di Saverio S. Nonoperative management of blunt splenic injury in adults: there is (still) a long way to go. The results of the Bologna-Maggiore Hospital trauma center experience and development of a clinical algorithm. Surg Today. 2015;45(10):1210-7.

77. Liu PP, Liu HT, Hsieh TM, Huang CY, Ko SF. Nonsurgical management of delayed splenic rupture after blunt trauma. J Trauma. 2012;72(4):1019-23.

78. Becker A, Lin G, McKenney MG, Marttos A, Schulman CI. Is the FAST exam reliable in severely injured patients? Injury. 2010;41(5):479-83.

79. Salim A, Teixeira PGR, DuBose J, Ottochian M, Inaba K, Margulies DR, Demetriades D. Predictors of positive angiography in pelvic fractures: a prospective study. J Am Coll Surg. 2008;207(5):656-62.

80. Mizushima Y, Tohira H, Mizobata Y, Matsuoka T, Yokota J. Fluid resuscitation of trauma patients: how fast is the optimal rate? Am J Emerg Med. 2005;23:833-7.

81. Vécsei V, Arbes S, Aldrian S, Nau T. Chest injuries in polytrauma. Eur J Trauma. 2005;31(3):239-43.

82. Olthof DC, van der Vlies CH, Joosse P, van Delden OM, Jurkovich GJ, Goslings JC. Consensus strategies for the nonoperative management of patients with blunt splenic injury: a Delphi study. J Trauma Acute Care Surg. 2013;74(6):1567-74.

83. Mutschler M, Hoffmann M, Wölfl C, Münzberg M, Schipper I, Paffrath T, Bouillon B, Maegele M. Is the ATLS classification of hypovolaemic shock appreciated in daily trauma care? An online-survey among 383 ATLS course directors and instructors. Emerg Med J. 2015;32(2):134-7.

84. Bland RD. Shoemaker WC, Abraham E, Cobo JC. Hemodynamic and oxygen transport patterns in surviving and nonsurviving postoperative patients. Crit Care Med. 1985;13(2):85-90.

85. Pommerening MJ, Goodman MD, Holcomb JB, Wade CE, Fox EE, del Junco DJ, Brasel KJ, Bulger EM, Cohen MJ, Alarcon LH, Schreiber MA, Myers JG, Phelan HA, Muskat P, Rahbar M, Cotton BA. Clinical gestalt and the prediction of massive transfusion after trauma. Inj Int J Care Inj. 2015;46:807-13.
86. Meredith JW, Young JS, Bowling J, Roboussin D. Nonoperative management of blunt hepatic trauma: the exception or the rule? J Trauma. 1994;36(4):529-35.

87. Moore FA, Davis JW, Moore EE, Cocanour CS, West MA, McIntyre MC. Western Trauma Association (WTA) critical decisions in trauma: management of adult blunt splenic trauma. J Trauma. 2008;65(5):1007-11.

88. Yucel N, Lefering R, Maegele M, Vorweg M, Tjardes T, Ruchholtz S, et al. Trauma Associated Severe Hemorrhage (TAS)score; probability of massive transfusion as surrogate for life threatening hemorrhage after multiple trauma. J Trauma. 2006;60:1228-36.

89. Numez TC, Voskresensky IV, Dossett LA, Shimall R, Dutton WD, Cotton BA. Early prediction of massive transfusion in trauma simple as ABC (assessment of blood consumption). J trauma. 2009;66:346-52 19-20.

90. Callcut RA, Cripps MW, Nelson MF, Conroy AS, Robinson BB, Cohen MJ. The massive transfusion score as a decision aid for resuscitation: learning when to turn the massive transfusion protocol on and off. J Trauma Acute Care Surg. 2016;80(3):450-6.

91. Brockamp T, Nienaber U, Mutschler M, Wafaisade A, Peiniger S, Lefering R, Bouillon B, Maegele M, Dgu T. Predicting on-going hemorrhage and transfusion requirement after severe trauma: a validation of six scoring systems and algorithms on the TraumaRegister DGU(R). Crit Care. 2012;16:R129.

92. Mutschler M, Nienaber U, Brockamp T, Wafaisade A, Fabian T, Paffrath T, Bouillon B, Maegele M, TraumaRegister DGU. Renaissance of base deficit for the initial assessment of trauma patients: a base deficit-based classification for hypovolemic shock developed on data from 16,305 patients derived from the TraumaRegister DGU ${ }^{\circledR}$. Crit Care. 2013;17(2):R42.

93. Joseph B, Haider A, Ibraheem K, Kulvatunyou N, Tang A, Azim A, O'keeffe T, Griess L, Vercruysse G, Rhee P. Revitalizing vital signs; the role of Delta Shock Index. Shock. 2016;46(3 Suppl 1):50-4. 